\title{
Statistical downscaling to project extreme hourly precipitation over the UK
}

Markus $\mathrm{Rau}^{1}, \mathrm{Yi} \mathrm{He}^{1}$, Clare Goodess $^{2}$ and András Bárdossy ${ }^{3}$

${ }^{1}$ Tyndall Centre for Climate Change Research, School of Environmental Sciences, University of East Anglia, Norwich, UK

Address: Öchslinstraße 34, 73033 Göppingen, Germany

Email: markusrau-gp@t-online.de

Phone: 0049 - 7161 - 9245339

${ }^{2}$ Climatic Research Unit, School of Environmental Sciences, University of East Anglia, Norwich, UK

${ }^{3}$ Institute for Modelling Hydraulic and Environmental Systems, Universität Stuttgart, Stuttgart, Germany

KEYWORDS: Regional climate change -Extreme precipitation events - Statistical downscaling

The first author of this paper was financially supported by the studentship provided by the Tyndall Centre for Climate Change Research.

This article has been accepted for publication and undergone full peer review but has not been through the copyediting, typesetting, pagination and proofreading process which may lead to differences between this version and the Version of Record. Please cite this article as doi: $10.1002 /$ joc.6302

This article is protected by copyright. All rights reserved. 


\section{Abstract}

Observed trends, theory and modelling results all suggest increases in future extreme precipitation due to climate warming. The largest increases are expected in short-duration events with less than a day. Relatively few previous studies have focused specifically on the projection of sub-daily precipitation extremes. In this study, a statistical downscaling method based on circulation patterns (CPs) is developed to project site-specific extreme hourly precipitation over the UK. First, a CP-classification categorizes extreme hourly precipitation events based on the underlying atmospheric pressure conditions on each day. An analogue day method is then used to find for each future day the most similar day in the past by comparing the predictor values of daily precipitation and temperature simulated by Regional Climate Models (RCMs) with observations conditioned on different CPs and seasons. Finally, the maximum hourly precipitation records on the most similar days are extracted and perturbed using precipitation duration-temperature relationships. The applied statistical downscaling method is a combination of the analogue and the regression-based method. It is found that the statistical downscaling method is able to reproduce observed extreme hourly precipitation. In terms of future changes under a 
warmer climate, it is shown that increases in extreme hourly precipitation can be as high as $112 \%$ but are highly variable depending on the rainfall stations, the future time periods, the emission scenarios, and the different RCM runs. 


\section{Introduction}

On a global scale, extreme precipitation is expected to become more intense due to climate warming (Seneviratne et al., 2012). This is physically plausible under the assumption that higher temperature can lead to increases in the atmospheric moisture content and evapotranspiration (Maraun et al., 2008) resulting in convective precipitation increases (Berg et al., 2013; Molnar et al., 2014). Convective precipitation events are often associated with sub-daily precipitation extremes (Beck and Bárdossy, 2013; Chan et al., 2014; Lenderink and van Meijgaard, 2008), which raises concerns about an increasing risk of flash floods in urban environments, fast responding river catchments, or industrial facilities that can be subject to water damage. For example, Lenderink and van Meijgaard (2008) demonstrated that changes in short-duration precipitation extremes may well exceed expectations from the Clausius-Clapeyron relation (7\% increase per one degree warming) by analyzing hourly precipitation data. They found increases of $14 \%$ in extreme hourly precipitation per one degree warming in large parts of Europe. Such super Clausius-Clapeyron relation may be explained by the release of latent heat within convective storms (Kendon et al., 2018). Not only temperature can affect extreme precipitation, but other factors such as changes in atmospheric circulation (Chan et al., 2016; Blenkinsop et al., 2015; de Lima et al., 2014), precipitable water (Bao et al., 2017), soil moisture and potential feedbacks (Kendon et al., 2010) need to be considered in a changing climate. 
Global climate models (GCMs) are commonly used to simulate future climate, including precipitation, by taking into account the effects of a changing concentration of greenhouse gases in the atmosphere. GCM based projections provide spatially consistent information for all regions and aim to simulate large-scale modes of variability, e.g. the El-Nino-Southern Oscillation (ENSO) and the monsoon systems. In terms of precipitation extremes, however, the spatial resolution of GCMs is too coarse to represent all the relevant physical processes, e.g. cyclones or convective events (Maraun, 2019; Goodess, 2012; Maraun et al., 2010b). As a consequence, downscaling techniques are needed to increase the coarse resolution and improve the poor representation of GCM simulated precipitation. Dynamical and statistical downscaling are the two commonly used downscaling techniques.

Dynamical downscaling uses output from a GCM to drive a regional climate model (RCM) with a higher spatial resolution over a limited area of interest. RCMs aim to represent the same atmospheric and physical processes as the GCMs. A RCM is driven by a range of atmospheric parameters provided by the GCM at the boundaries of the RCM, which generally leads to good agreement between the large-scale fields in the RCM and the driving GCM (Buonomo et al., 2007). Differences in the GCM outputs can have considerable impacts on the RCM outputs (Deidda et al., 2013). For example, Kendon et al. (2012) noted that a shift in the GCM simulated storm tracks lead to considerable changes in the precipitation projections over the UK. In order to allow an isolated and more comprehensive assessment of the RCM performances, RCMs can 
also be driven by reanalysis data (quasi observed boundary conditions) (Maraun et al., 2010b). Discrepancies can occur between different RCMs due to differences in the model formulation or small-scale internal variability within the RCMs. But even if the simulated results agree with each other, it may still be that there are missing processes and deficiencies common to all RCMs. For example, RCMs are not able to explicitly resolve processes such as radiation, convection, cloud microphysics and land atmosphere interaction. Instead, parameterization schemes are applied to simplify the complexity of the real world processes, which contributes to model uncertainties. RCMs tend to overestimate the occurrence of wet days due to the drizzle effects resulting in an overestimation of the precipitation mean (Buonomo et al., 2007). RCMs are also limited in the simulation of convective precipitation events (Svoboda et al., 2016; Maraun et al., 2010b), which is important for the representation of extreme hourly precipitation (Chan et al, 2013). As a consequence, large differences between RCM simulated and observed hourly precipitation extremes are found (Svoboda et al., 2017; Chan et al., 2014; Gregersen et al., 2013; Hanel and Buishand, 2010). In order to overcome the current limitations in terms of RCM precipitation projections, high resolution ( $1 \mathrm{~km}$ to $5 \mathrm{~km}) \mathrm{RCMs}$ have been tested (Prein et al., 2017; Ban et al., 2015). Clouds and convection can be better resolved and the diurnal precipitation tend to be better reproduced at higher resolutions (Seneviratne et al., 2012). As a result, RCMs at $1.5 \mathrm{~km}$ are able to simulate extreme hourly precipitation more realistically compared to $12 \mathrm{~km}$ RCMs (Kendon et al., 2016; Chan et al., 2014; Kendon et al., 
2014). But even the latest high resolution RCMs cannot provide site-specific projections of precipitation extremes and therefore may still misrepresent localized precipitation events. Besides, the computational demand limits the number of runs a high resolution RCM can have and thus the internal variability may be underestimated. Due to these issues precipitation, and especially extreme precipitation, modelled by RCMs need to be applied with great caution and statistical downscaling techniques can be considered as an alternative or, as here, an additional and complementary method (Hanel and Buishand, 2010).

Statistical downscaling methods are able to provide projections of precipitation extremes at local-scale. They often combine large-scale atmospheric (e.g. sea level pressure) and surface variables (e.g. temperature) simulated by climate models to project precipitation extremes. In the past, most studies focused on the downscaling of daily precipitation, whereas only few attempted to project sub-daily precipitation. Among those, Haberlandt et al. (2014) used a statistical model to reproduce sub-daily precipitation extremes and relied on the RCM simulated changes in hourly precipitation to predict future changes. Similarly, Peleg et al. (2019) calculated factors of change from different RCMs to reparameterize an hourly weather generator. Mezghani and Hingray (2009) applied a regression-based model to simulate daily precipitation and disaggregated daily to sub-daily precipitation based on an analogue day method. Willems and Vrac (2011) assessed different analogue day methods to project sub-daily precipitation extremes. The best performances were found for the method which used daily 
precipitation conditioned on circulation patterns (CPs) as the predictor to find the analogue day. The principle of the analogue day method is to find the most similar weather situation in the past and then use the corresponding local-scale observation as the projected value. The main advantage of the analogue day method is that it captures physical coherence between the predictor and predictand, and spatial coherence between different sites (Maraun et al., 2010b). It is able to simulate infrequent but observed extreme hourly precipitation (Mezghani and Hingray, 2009) by not making restrictive assumption of the precipitation distribution (Gangopadhyay et al., 2005). RCM simulated precipitation intensities which can be heavily biased (Buonomo et al., 2007; Maraun et al., 2010b) are only used to find the analogue day. The analogue day method is also a comparatively simple technique to apply (Zorita and Von Storch, 1999). However, the common analogue day method is only able to reproduce precipitation values which have been observed in the past. This is particularly problematic for the projection of precipitation extremes as they are expected to increase in the future. In order to overcome this limitation, perturbation factors can be used. For example, Willems and Vrac (2011) applied the Clausius-Clapeyron relation to perturb the observed sub-daily precipitation for each analogue day. The statistical downscaling technique used in this study to project extreme hourly precipitation is based on the analogue day method by using a new perturbation approach. 
This paper is organized as follows. In Section 2, the observed and RCM simulated data sets used to estimate UK extreme hourly precipitation are described. Section 3 explains the fuzzy rulebased CP-classification method and the statistical downscaling method developed in this study. In Section 4, the results of four different approaches to find the analogue day are compared. The approach that reproduces key characteristics of observed precipitation extremes most realistically is used for the projection of UK extreme hourly precipitation presented in Section 5. The last section summarizes the main findings and discusses the potential of future developments.

\section{Data description}

The observed precipitation for the time period 1980-2009 were obtained from the UK Met Office Integrated Data Archive System (MIDAS) Land Surface Stations database (http://browse.ceda.ac.uk/browse/badc/ukmo-midas). The data set contains more than 12,000 stations with daily precipitation and 530 stations with hourly precipitation records in the UK. A number of quality control and pre-screening steps were undertaken in this study to eliminate suspicious precipitation records and to provide homogeneous precipitation time series (see supporting information Text S1).

This article is protected by copyright. All rights reserved. 
A number of criteria were then defined to select the hourly precipitation stations with a high level of data completeness and quality:

1. Only stations with no single missing year and less than $5 \%$ missing values for the time period 1980-2009 are considered. A large number of hourly precipitation stations in the UK started to record in the early 1980s, and hence the period 1980-2009 was chosen.

2. Only stations with consistent hourly and daily precipitation records are considered. The hourly precipitation time series were aggregated to daily time series and compared with the corresponding daily time series. The Pearson correlation coefficient $\rho_{X, Y}$ and the normalized root-mean-square deviation (NRMSD) were calculated. Only the stations with $\rho_{X, Y} \geq 0.9$ and NRMSD $\leq 0.05$ were used in this study.

3. The RHtest as described in Etccdi.pacificclimate.org (2012) was applied to identify and eliminate stations with an inhomogeneous time series.

4. For each of the 14 UK extreme precipitation regions defined by Jones et al. (2014), only the station with the highest completeness of hourly precipitation records was used.

For twelve of the 14 UK extreme precipitation regions, at least one station fulfilled the station selection criteria. The two regions that are not represented by any station in this study are Mid Wales and South Scotland. The twelve finally selected UK hourly precipitation stations are shown in Figure 1. The seasonal cycles of extreme hourly precipitation (defined in this study as the precipitation at or above the $99.5^{\text {th }}$ percentile) for the twelve selected stations are 
illustrated in Figure 2. The stations at Tiree, Valley and Camborne do not exhibit much seasonal difference. These three stations are most exposed to the North Atlantic and thus more under the influence of a maritime climate. It is likely that they are less affected by convective precipitation extremes (Chan et al., 2013). In contrast, the stations at Kinloss, Leuchars, Aldergrove, Boulmer, Cranwell, Marham, and Northolt exhibit a pronounced maxima of hourly precipitation extremes for the warmest months (JJA) of the year. Summer precipitation extremes can often be linked with increased convective activity (Chan et al., 2014). Two seasons are defined, namely winter (NDJFMA) and summer (MJJASO), on which the statistical downscaling method is conditioned. Using more than two seasons would reduce the robustness of the statistical downscaling method and is thus not considered in this study.

The $5^{\circ}$ gridded sea level pressure (SLP) data (Hurrell and Trenberth, 2013) were obtained from the National Center for Atmospheric Research (NCAR) for the fuzzy rule-based CP-classification (Rau, 2016). The NCAR SLP dataset provides the longest continuous daily gridded Northern Hemisphere sea-level pressure data starting from 1899.

Daily mean temperature was extracted from the E-OBS data set v10.0 (Haylock et al., 2008). The E-OBS daily mean temperature is defined as the mean between the daily maximum and minimum temperature from 0000UTC to 0000UTC of the following day, which is line with the RCM simulated daily mean temperature data. For each of the twelve stations, only the E-OBS grid point with the smallest distance to the respective station was used. 
The regional climate model ( $R C M)$ data sets used in this study were obtained from the CORDEX data archive (http://www.cordex.org/). The EURO-CORDEX (Jacob et al., 2014) is the European branch of the international CORDEX initiative (Giorgi et al., 2009). It provides RCM data on a $0.11^{\circ}$ (EURO-11) and $0.44^{\circ}$ (EUR-44) spatial grid. In this study, the RCA4 RCM and the RACMO22E RCM are used, both at $0.11^{\circ}$ spatial resolution. They both cover the time period from 1980-2009, which is used as the calibration and validation period in this study. The RCA4 was developed in Sweden by the Rossby Centre at the Swedish Meteorological and Hydrological Institute (SMHI) and is the fourth version of the Rossby Centre's RCMs. The RACMO22E was developed in the Netherlands by the Royal Netherlands Meteorological Institute (KNMI). The version used in this study is an update of the RACMO2 version. The two RCMs are either driven by ERA-interim reanalysis or global climate model (GCM) data. The ERA-interim driven RCM runs cover the time period 1980-2010 (RCA4) and 1979-2012 (RACMO22E). The GCM driven RCMs runs cover the reference time period 1980-2005 and the future time period 2006-2100. The climate simulations for the future time period are run under two different emission scenarios, namely RCP4.5 and RCP8.5. This study used four different GCM driven RCM data, namely the CM5A-MR driven RCA4, the ESM-LR driven RCA4, the EC-Earth driven RCA4, and the EC-Earth driven RACMO22E.

\section{The statistical downscaling method}


A fuzzy rule-based classification of synoptic atmospheric conditions is used to categorize five CPs and their corresponding relationships to UK extreme hourly precipitation as described in Rau (2016). Objective functions are incorporated in the fuzzy rule-based classification process to optimise the quality of the CP-classification in distinguishing between dry and wet CPs. In order to evaluate the quality of the fuzzy rule-based CP-classification, information measures are applied. In general, objective functions and information measures focus on mean precipitation characteristics. In this study, one information measure is modified to specifically reflect on the CP-classification's quality to identify extreme precipitation events. This information measure assesses how well the CP-classification distinguishes between CPs with a high extreme precipitation event probability and those CPs with a low probability of extreme precipitation events. Extreme precipitation is defined as an event exceeding the threshold of $10 \mathrm{~mm} / \mathrm{hr}$.

$\mathrm{CP} 1$ and $\mathrm{CP} 4$ are characterized by low pressure systems, CP2 and CP3 are associated with high pressure systems and CP5 features westerly airflow over the UK. It was shown that the highest extreme precipitation probabilities were found for the two CPs that are associated with low pressure systems (CP1 and CP4) over the UK (Rau, 2016). The concept of a fuzzy rule-based CPclassification has been also used in previous studies (Bárdossy, 2010; Bárdossy and Pegram, 2011; Haberlandt et al., 2014). For a detailed description of the theoretical background and the methodology, the reader is referred to (Bardossy et al., 1995; Bárdossy et al., 2002). 
As explained in other studies (Bárdossy, 2010; Haberlandt et al., 2014), the relationship between CPs and precipitation extremes is unlikely to remain the same in the future climate and therefore using CPs as the only predictor is not sufficient to project changes in hourly precipitation extremes. Daily precipitation and temperature are used as additional predictors in this study. Figure 3 gives an overview of the methodology. The left part of the figure explains the calibration of the fuzzy rule-based CP-classification and the statistical downscaling method. The right part illustrates the estimation of extreme hourly precipitation based on the RCM simulated predictor variables. The applied statistical downscaling method is a combination of the analogue and the regression-based method. The observed precipitation events are subsampled into a number of CPs and two seasons (or twelve calendar months). The daily precipitation and temperature are used as combined predictors to find the most similar day (analogue day) in the past. The use of temperature as a predictor is important because hourly precipitation extremes are likely to be more intensified by increasing temperature compared to daily extremes (Westra et al., 2014).

Four different approaches of subsampling are compared (see Table 1). M1 subsamples each calibration day into each $\mathrm{CP}$ and each season, whereas $\mathrm{M} 2$ uses calendar months instead of seasons. In both $\mathrm{M} 1$ and $\mathrm{M} 2$, each calibration day $t_{C}$ in the past is characterized by its normalized daily precipitation $n P\left(t_{C}\right)$ and temperature $n T\left(t_{C}\right)$. On a given day $t$ for which hourly precipitation is estimated, the normalized daily precipitation $n P(t)$ and temperature 
$n T(t)$ are calculated as described in Equation 1 and Equation 2 respectively. The distance $D_{P T}\left(t, t_{C}\right)$ in terms of daily precipitation and temperature between a given day $t$ and a calibration day $t_{C}$ within the respective subsample is calculated using Equation 3. The calibration day on which the distance is smallest is chosen as the analogue day. In case when several days show the same minimal distance to the given day, the analogue day is randomly chosen among those days. The selected analogue days are station-specific as the predictor variables (daily precipitation and temperature) are different at each station.

$$
n P(t)=\frac{P(t)-\min \left(P_{S, C P}\right)}{\max \left(P_{S, C P}\right)-\min \left(P_{S, C P}\right)}
$$

Where $n P(t)$ is the normalized daily precipitation for a given day $t$ (or calibration day $t_{C}$ ); $P(t)$ is the daily precipitation for a given day $t$ (or calibration day $t_{C}$ ); $P_{S, C P}$ is the subsample of daily precipitation values for a given season $S$ and $C P$ over the calibration period. In M2 and M4, season $S$ is replaced by month $M$.

$$
n T(t)=\frac{T(t)-\min \left(T_{S, C P}\right)}{\max \left(T_{S, C P}\right)-\min \left(T_{S, C P}\right)}
$$

Where $n T(t)$ is the normalized daily temperature for a given day $t$ (or calibration day $t_{C}$ ); $T(t)$ is the daily temperature for a given day $t$ (or calibration day $t_{C}$ ); $T_{S, C P}$ is the subsample of daily temperature values for a given season $S$ and $C P$ over the calibration period. In M2 and M4, season $S$ is replaced by month $M$. 


$$
D_{P T}\left(t, t_{C}\right)=\left(n P(t)-n P\left(t_{C}\right)\right)^{2}+\left(n T(t)-n T\left(t_{C}\right)\right)^{2}
$$

Where $D_{P T}\left(t, t_{C}\right)$ is the distance between a given day $t$ and calibration day $t_{C}$ in terms of daily precipitation and temperature.

The subsampling approaches M3 and M4 use daily precipitation as an additional subsample criterion. Similar to $\mathrm{M} 1$ and $\mathrm{M} 2$, each calibration day is first subsampled into each $\mathrm{CP}$ and each season (M3) or month (M4). Subsequently, the subsampling process is extended with six daily precipitation categories in M3 and M4. The reason for using daily precipitation categories is that RCMs cannot be expected to simulate daily precipitation intensities accurately (Fowler and Ekström, 2009; Maraun et al., 2010b). Therefore, using daily precipitation categories, instead of daily precipitation intensities, may improve the performance of the statistical downscaling process. The daily precipitation categories are defined as follows:

- The first category includes all the calibration days with daily precipitation below $1.0 \mathrm{~mm}$.

- The second category contains the days with daily precipitation exceeding or equal to $1.0 \mathrm{~mm}$ and below the $20^{\text {th }}$ percentile.

- The third, fourth and fifth category includes days with daily precipitation between the $20^{\text {th }}$ and $40^{\text {th }}, 40^{\text {th }}$ and $60^{\text {th }}, 60^{\text {th }}$ and $80^{\text {th }}$ percentile, respectively.

- The sixth category comprises all the days with daily precipitation exceeding or equal to the $80^{\text {th }}$ percentile. 
The different percentiles of daily precipitation are determined separately for each subsample of $\mathrm{CP}$ and season (M3) or month (M4). In M3 and M4, each calibration day within a certain CP, season (or month) and precipitation category is only characterized by its normalized temperature value $n T\left(t_{C}\right)$. As a result, the distance $D_{T}\left(t, t_{C}\right)$ between a given day and a calibration day is only calculated in terms of daily temperature (see Equation 4). The calibration day for which the distance $D_{T}\left(t, t_{C}\right)$ is minimal is selected as the analogue day.

$$
D_{T}\left(t, t_{C}\right)=\left(n T(t)-n T\left(t_{C}\right)\right)^{2}
$$

Where $D_{T}\left(t, t_{C}\right)$ is the distance between a given day $t$ and calibration day $t_{C}$ in terms of temperature.

The process of perturbing the observed hourly precipitation records is based on precipitation duration and temperature relationships. Precipitation duration often decreases with higher temperature (Hardwick Jones et al., 2010; Beck and Bárdossy, 2013). By perturbing the observed hourly precipitation records, the statistical downscaling method should be capable of projecting extreme precipitation events that have not been observed in the past. For this purpose, a linear regression is fitted using an ordinary least squares approach to represent precipitation duration (in hours) as a function of daily temperature for each station, season and CP separately. If the linear regression fulfils the $5 \%$ significance criterion based on the p-value test and its root mean square error (RMSE) value is smaller than 1, the linear regression slope $\beta_{S, S, C P}$ for a given station, season and $\mathrm{CP}$ is used. Otherwise, the linear regression slope is 
calculated unconditional of the given CP. For a detailed summary of the regression analysis, the interested reader is referred to Rau (2016).

In the next step, the observed maximum hourly precipitation record on the analogue day is perturbed as described in Equation 5 and Equation 6. The perturbed maximum hourly precipitation value $M H P(t)$ represents the estimated hourly precipitation for a given day $t$.

$$
P D(t)=P D_{\text {analogue }}+\left(T(t)-T_{\text {analogue }}\right) \times \beta_{s, S, C P}=1,2,3, \ldots, 24
$$

Where $P D(t)$ is the estimated precipitation duration on a given day $t ; P D_{\text {analogue }}$ is the observed precipitation duration on the analogue day; $T(t)$ is the temperature on a given day $t$; $T_{\text {analogue }}$ is the temperature on the analogue day; $\beta_{S, S, C P}$ is the statistically significant regression slope conditioned on station $s$, season $S$ and $C P$ (or alternatively station $s$ and season $S)$.

$$
M H P(t)=M H P_{\text {analogue }} \times \frac{P D_{\text {analogue }}}{P D(t)}
$$

Where $M H P(t)$ is the perturbed maximum hourly precipitation value on a given day $t$; $M H P_{\text {analogue }}$ is the observed maximum hourly precipitation value on the analogue day.

In order to validate the statistical downscaling method, the differences between the $99.5^{\text {th }}$ percentile of the observed and estimated maximum hourly precipitation value are averaged over 100 bootstrapping samples. Each bootstrapping sample consists of the same number of 
validation days. Those validation days are selected with replacement from the total population of validation days for each of the 100 bootstrapping samples separately. It means that in each bootstrapping sample, some validation days exist multiple times whereas others are not included at all.

\section{Results}

In the following, the results of the statistical downscaling method to estimate site-specific extreme hourly precipitation are presented. At first, the estimates are derived from ERAinterim driven RCM data under quasi-observed boundary conditions. Similarly to the quantile verifications score described in Maraun et al. (2010a), the differences between the $99.5^{\text {th }}$ percentiles of the observed and estimated hourly precipitation are assessed in order to validate the performance of the statistical downscaling method. Table 2 shows the $99.5^{\text {th }}$ percentile differences averaged over 100 bootstrapping samples for each of the RCA4 and the RACMO22E RCM run. The differences are assessed for the ten warmest summers for each station between 1980 and 2009. This is to test the assumption that the statistical downscaling method remain valid under a warming climate. Overall, the estimated extreme hourly precipitation show good agreement with the observed extremes. M1 leads to the best results on average for the two RCMs and the twelve different stations. The same holds true for the estimates based on 
observed predictors (see Table 3). Therefore in the following, the subsampling approach M1 is used to project extreme hourly precipitation.

It should be noted that the mean temperature of the 10 warmest summers is only higher than the 20 coldest summers by $0.8^{\circ} \mathrm{C}$ to $1.3^{\circ} \mathrm{C}$ depending on the station for the time period 1980 2009. In contrast, the projected temperature increases in summer averaged over the four different GCM driven RCMs for the future time period 2075-2100 under the emission scenario RCP8.5 are between $2.2^{\circ} \mathrm{C}$ and $3.4^{\circ} \mathrm{C}$ in comparison to the reference period $1980-2005$. As a consequence, the ability of the downscaling method to project extreme hourly precipitation under a warmer climate which could be much warmer than the one it was calibrated on, can only be assessed to a limited degree.

In terms of the RCM predictors, it can be found that the daily precipitation variable is considerably overestimated by the RCA4 RCM in summer (see Figure 4) and winter (not shown). Daily temperature tend to be underestimated by both, the RCA4 and the RACMO22E RCM, in summer (see Figure 5) and winter (not shown). However, any biases in the RCM predictor variables are unlikely to have an adverse effect on the estimates of hourly precipitation as the statistical downscaling process uses normalized values of the predictor variables. Regarding the large-scale atmospheric variability, the observed CP frequencies are realistically reproduced by both RCMs in summer (see Table 4) and winter (not shown). 
Projections are produced for two different future time periods, 2030-2055 and 2075-2100, derived from four different GCM driven RCM data sets. Three different combinations of the time periods and RCPs include 2030-2055 (RCP4.5), 2075-2100 (RCP4.5) and 2075-2100 (RCP8.5). For the future time period 2030-2055, only the emission scenario RCP4.5 is considered because the respective changes in the climate are expected to be similar over this time period between the different emission scenarios (Kirtman et al., 2013). For this time period and emission scenario, the simulated daily temperature increase in summer averaged over the four different $\mathrm{GCM}$ driven $\mathrm{RCMs}$ ranges from $0.7^{\circ} \mathrm{C}$ (Tiree) to $1.1^{\circ} \mathrm{C}$ (Boscombe Down, Northolt and Marham). For the future time period 2075-2100, two different emission scenarios (RCP4.5 and RCP8.5) are considered. The average simulated daily temperature increase in summer for $2075-2100$ under RCP4.5 is between $1.3^{\circ} \mathrm{C}$ (Tiree) and $1.7^{\circ} \mathrm{C}$ (Boscombe Down, Northolt, Marham and Cranwell). For 2075-2100 under the high emission scenario RCP8.5, the average daily temperature increase in summer ranges from $2.2^{\circ} \mathrm{C}$ (Tiree) to $3.4^{\circ} \mathrm{C}$ (Boscombe Down and Northolt).

In terms of the GCM driven RCM projections of daily precipitation extremes $\left(99.5^{\text {th }}\right.$ percentile) in summer (Table 5) and winter (not shown), results vary for 2030-2055 under RCP4.5, mostly increases are simulated for 2075-2100 under RCP4.5 and only increases are projected for 20752100 under RCP8.5. It seems reasonable that the increases in daily precipitation extremes are most pronounced for the future scenario, where the temperature increases are most dominant. 
Table 6 summarizes the changes in the estimated medians of extreme hourly precipitation $\left(99.5^{\text {th }}\right.$ percentile) over 100 bootstrapping samples for each station and GCM driven RCM data set. Figure S1-S4 illustrates the ranges of the 100 different bootstrapping samples for each station and GCM driven RCM data set. The projections include three combinations, namely 2030-2055 (RCP4.5), 2075-2100 (RCP4.5) and 2075-2100 (RCP8.5), respectively. Similarly to daily extreme precipitation, increases in extreme hourly precipitation are most pronounced for 2075-2100 (RCP8.5), which coincides with the strongest temperature increase. For 2075-2100 (RCP8.5), all twelve stations exhibit increases in extreme hourly precipitation for all RCM-GCM combinations and the future increases are higher in magnitude compared to 2030-2055 (RCP4.5) and 2075-2100 (RCP4.5). Regarding 2030-2055 and 2075-2100 under RCP4.5, the increases in extreme hourly precipitation clearly outweigh the small number of decreases projected for certain stations using certain GCM driven RCM data sets. In terms of magnitude, future increases in extreme hourly precipitation tend to be higher for 2075-2100 (RCP4.5) compared to 2030-2055 (RCP4.5). The average increases in extreme hourly precipitation for 2075-2100 (RCP8.5) can be as high as $112 \%$ at Kinloss based on the EC-EARTH driven RCA4. But results can highly vary between the four different GCM driven RCM data sets. For example, estimates based on the CM5A-MR driven RCA4 suggest only an average increase of $37 \%$ for Kinloss and 2075-2100 (RCP8.5). There are no considerable differences in the simulated future responses of the three predictor variables amongst the four different GCM driven RCM data 
sets in summer (see Figure S5-S7) and winter (not shown). This suggests it is likely that certain weather conditions with the potential of causing extreme hourly precipitation occur more often in some GCM driven RCMs than in others. For example, at Kinloss 19 summer days with daily spatially averaged precipitation between $8 \mathrm{~mm}-15 \mathrm{~mm}$, daily mean temperature between $14.2^{\circ} \mathrm{C}-16^{\circ} \mathrm{C}$ and westerly airflow over the UK (CP5) are simulated by the EC-EARTH driven RCA4 for the time period 2075-2100 under RCP8.5. In contrast, only four days with the same predictor characteristics are found in the CM5A-MR driven RCA4. Those particular predictor characteristics lead to an estimated extreme event of $16.2 \mathrm{~mm} / \mathrm{hr}$ for the station at Kinloss.

Future increases in hourly precipitation extremes also exhibit high spatial variability. Figure 6 shows the changes of the estimated median of the $99.5^{\text {th }}$ hourly precipitation percentile based on the 100 bootstrapping samples for 2030-2055 (RCP4.5), 2075-2100 (RCP4.5) and 2075-2100 (RCP8.5). Overall, the average increases at Tiree are the smallest. They are $0 \%, 5 \%$ and $12 \%$ for 2030-2055 (RCP4.5), 2075-2100 (RCP4.5) and 2075-2100 (RCP8.5), respectively. This station is highly exposed to the North Atlantic and less likely to be affected by convective precipitation events, which may explain why it exhibits the smallest increases. The highest increases can be found at Kinloss. They are 19\%, 44\% and 75\% for 2030-2055 (RCP4.5), 2075-2100 (RCP4.5) and 2075-2100 (RCP8.5), respectively. Two other stations, namely Eskdalemuir and Northolt, also show strong increases in future extreme hourly precipitation. It is interesting to note that Kinloss, Eskdalemuir and Northolt are not only the three stations with the highest increases in 
extreme hourly precipitation but also the stations with the highest maximum hourly precipitation records in the past (1980-2009). It seems reasonable that those stations that have experienced the most extreme precipitation events in the past will be most affected by warmer and thus more extreme conditions in the future. Kinloss is the station furthest north in this study and temperature tend to be lower resulting in reduced convective activity compared to stations in the south. However, under a warmer climate, convective activity will increase and extreme precipitation will be intensified. Similarly at Eskdalemuir, the observed temperature values are lower compared to stations in the south and convective activity can be expected to be reduced. The limited sampling variability of convective precipitation events in the past may explain the high variability of future increases in hourly precipitation extremes among the 100 bootstrapping samples at Kinloss and Eskdalemuir (see Figure S3 and S4). The third station with high increases in extreme hourly precipitation is Northolt. This station is located in London, where the urban environment considerably influences the local climate (Kendon et al., 2018). This may explain the higher increases at Northolt compared to the nearby station at Boscombe Down. Northolt is also the station with the highest mean and extreme temperature records. Therefore, strong convective activity can be expected at this station. We suggest that the high increases in extreme hourly precipitation at Kinloss, Eskdalemuir and Northolt can be strongly linked with changes in the frequency occurrence and intensity of convective precipitation events under a future warmer climate. This is in line with previous studies (Berg et al., 2013; 
Lenderink and van Meijgaard, 2008) that found high increases in convective precipitation beyond the $7 \%$ increase per degree temperature suggested by the Clausius-Clapeyron relationship.

In order to assess the contribution of the final perturbation process based on precipitation duration and temperature relationships (see Equation 5 and Equation 6), Table 7 shows the differences between the estimates of extreme hourly precipitation using the perturbation process and the estimates not using the perturbation process. As expected, perturbing the observed hourly precipitation records leads to higher projections of extreme hourly precipitation in most cases. The differences tend to be highest for the future period $2075-2100$ under emission scenario RCP8.5. This is the future scenario with the highest temperature increase. However, it needs to be noted that the influence of the perturbation factor is small overall. Most of the differences between perturbed and non-perturbed estimates are smaller than $5 \%$ and are not statistically significant. It should be also mentioned that the three stations (Kinloss, Eskdalemuir and Northolt) with the highest increases in extreme hourly precipitation show very different responses to the perturbation process. This is probably due to the different geographical characteristics of the three stations.

\section{Conclusions}

This article is protected by copyright. All rights reserved. 
In this study, a CP-based statistical downscaling method is developed to project site-specific extreme hourly precipitation for twelve different stations. Daily precipitation and temperature conditioned on five (plus one unclassified) CPs are used as the predictors within the statistical downscaling process. In the second step, the daily maximum hourly precipitation on each analogue day is perturbed based on precipitation duration and temperature relationships. The estimated $99.5^{\text {th }}$ percentiles of extreme hourly precipitation by the statistical downscaling method are assessed over the ten warmest summers for the validation period 1980-2009. It is found that the statistical downscaling method is able to provide reliable estimates of extreme hourly precipitation under warmer conditions for both RCM data sets. Four different approaches of finding the analogue day are compared and the approach M1 obtained the best results. This approach subsamples all the available calibration days into two seasons, instead of using the twelve calendar months as a subsample criterion. In M1, the analogue days are found by using daily precipitation and temperature as equally important predictors.

In terms of future changes, extreme hourly precipitation is projected based on four different GCM driven RCM data sets, namely the CM5A-MR driven RCA4, the ESM-LR driven RCA4, the EC-EARTH driven RCA4 and the EC-EARTH driven RACMO22E. Two different future time periods, 2030-2055 and 2075-2100, and two different emission scenarios, RCP4.5 and RCP8.5, are considered. It is found that increases in extreme hourly precipitation are most pronounced for the future time period 2075-2100 under RCP8.5 which coincides with the strongest 
temperature increase. The increase in extreme hourly precipitation can be as high as $111.9 \%$ relative to the reference period $1980-2005$. It needs to be noted, however, that changes highly vary amongst the twelve stations. Projections of extreme hourly precipitation also vary between the four different GCM driven RCM data sets. This may be partly due to limitations in the statistical downscaling process and in the RCM simulated predictors.

One main limitation of the statistical downscaling process is the restricted time length (19802009) for calibration purposes of the downscaling method. It limits the number of extreme hourly precipitation events that can be included within the downscaling process. A longer calibration period would enable the downscaling method to represent a wide range of extreme events that can occur more often under a warmer climate. To overcome this limitation, the observed hourly precipitation records are perturbed based on precipitation duration and temperature to extrapolate extreme events in response to higher temperature. However, it could be argued that the duration-temperature relationships represent average weather conditions and the response to higher temperature may be very different under extreme weather conditions (e.g. thunderstorms).

In terms of the RCM simulated variables, both RCMs used in this study rely on parameterization schemes to simulate convective precipitation events. This leads to uncertainties (Maraun et al., $2010 b$ ) in the RCM daily precipitation variable, which is used as a predictor within the downscaling process. Using a larger number of RCMs could represent a better range of the 
uncertainties associated with the RCM based predictors. Another option is the use of very high resolution RCMs at ca. 1-5 km. Those RCMs are able to explicitly resolve convectional processes and hence represent convective precipitation events more realistically (Kendon et al., 2012). However, they still tend to overestimate hourly precipitation extremes (Kendon et al., 2014). Incorporating the output of the high resolution RCMs into the statistical downscaling process presented in this study could reduce the biases in the high resolution RCMs.

To enhance the reliability of the extreme hourly precipitation estimates presented in this study, additional predictor variables (e.g. measures of humidity or the Convective Available Potential Energy (CAPE) index) could be introduced into the statistical downscaling method. They can provide information of the moisture flux in the atmosphere and could improve the representation of convective precipitation events.

The statistical downscaling method developed in this study can be readily applied to assess the potential higher risk of flash floods in the future. It is able to project UK extreme hourly precipitation at any site for which observed hourly precipitation records are available. However, projections of extreme hourly precipitation can vary considerably between the different GCM driven RCM data sets. We therefore suggest that the projected changes in extreme hourly precipitation should be rather interpreted as indicative of the magnitude and direction. 


\section{Acknowledgments}

We acknowledge the use of UK observed hourly and daily precipitation records from the MIDAS Land Surface Stations database (http://browse.ceda.ac.uk/browse/badc/ukmo-midas), the use of the gridded SLP data set from the National Centre for Atmospheric Research climate data guide (https://climatedataguide.ucar.edu/climate-data/ncar-sea-level-pressure), the use of gridded daily mean temperature from the E-OBS data set (http://www.ecad.eu/download/ ensembles/ensembles.php), and the use of the RCM data sets from the EURO-CORDEX data archive (http://www.cordex.org/). The research presented in this paper was partly carried out on the High Performance Computing Cluster supported by the Research and Specialist Computing Support service at the University of East Anglia. The first author of this paper was financially supported by the studentship provided by the Tyndall Centre for Climate Change Research. We state that there is no conflict of interest to declare that might influence the authors' objectivity in this paper.

\section{Supporting information}

- Text S1: Quality control and pre-screening procedure of the observed hourly precipitation data 
- Figure S1-S4: Estimated $99.5^{\text {th }}$ percentiles of the daily maximum hourly precipitation based on GCM driven RCM data

- Figure S5: Simulated daily temperature frequency distributions in summer based on the four different GCM driven RCM data sets for the station at Boscombe Down

- Figure S6: Simulated daily precipitation frequency distributions in summer based on the four different GCM driven RCM data sets for the station at Boscombe Down

- Figure S7: Simulated CP frequencies in summer based on the four different GCM driven RCM data sets

\section{References}

Ban, N., Schmidli, J. \& Schaer, C. (2015). Heavy precipitation in a changing climate: Does short-term summer precipitation increase faster? Geophysical Research Letter 42: 1165-1172.

Bao, J., Sherwood, S., Alexander, L., \& Evans, J. (2017). Future increases in extreme precipitation exceed observed scaling rates. Nature Climate Change 7: 128-132.

Bárdossy, A., \& Pegram, G. (2011). Downscaling precipitation using regional climate models and circulation patterns toward hydrology. Water Resources Research 47(4): W04505.

Bárdossy, A. (2010). Atmospheric circulation pattern classification for South-West Germany using hydrological variables. Physics and Chemistry of the Earth, Parts A/B/C 35(9): 498-506. 
Bárdossy, A., Stehlík, J., \& Caspary, H.-J. (2002). Automated objective classification of daily circulation patterns for precipitation and temperature downscaling based on optimized fuzzy rules. Climate Research 23(1): 11-22.

Bárdossy, A., Duckstein, L., \& Bogardi, I. (1995). Fuzzy rule-based classification of atmospheric circulation patterns. International Journal of Climatology 15(10): 1087-1097.

Beck, F., \& Bárdossy, A. (2013). Indirect downscaling of hourly precipitation based on atmospheric circulation and temperature. Hydrology \& Earth System Sciences 17(12): 4851-4863.

Berg, P., Moseley, C., \& Haerter, J. (2013). Strong increase in convective precipitation in response to higher temperatures. Nature Geoscience 6(3): 181-185.

Blenkinsop, S., Chan, S., Kendon, E., Roberts, N., \& Fowler, H. (2015). Temperature influence on intense UK hourly precipitation and dependency on large-scale circulation. Environmental Research Letters 10: 054021.

Buonomo, E., Jones, R., Huntingford, C., \& Hannaford, J. (2007). On the robustness of changes in extreme precipitation over Europe from two high resolution climate change simulations. Quarterly Journal of the Royal Meteorological Society 133(622): 65-81.

Chan, S., Kendon, E., Roberts, N., Fowler, H., \& Blenkinsop, S. (2016). Downturn in scaling of UK extreme rainfall with temperature for future hottest days. Nature Geoscience 9: 24-28.

Chan, S. et al. (2014). The value of high-resolution Met Office regional climate models in the simulation of multihourly precipitation extremes. Journal of Climate 27(16): 6155-6174. 
Chan, S., Kendon, E., Fowler,H., Blenkinsop,S., Ferro,C., \& Stephenson,D. (2013). Does increasing the spatial resolution of a regional climate model improve the simulated daily precipitation? Climate Dynamics 41(5-6): 1475-1495.

de Lima, M., Santo, F., Ramos, A., \& Trigo, R. (2014). Trends and correlations in annual extreme precipitation indices for mainland Portugal, 1941-2007. Theoretical and Applied Climatology 119(1-2): 55-75.

Deidda, R. et al. (2013). Regional climate models' performance in representing precipitation and temperature over selected Mediterranean areas. Hydrology \& Earth System Sciences 17(12): 5041-5059.

Etccdi.pacificclimate.org [homepage on the internet]. Toronto: Climatic Research Division Environment Canada. [Cited 2012 March 03]. Available from: http://etccdi.pacificclimate.org/RHtest/RHtestsV3_UserManual.doc

Fowler, H., \& Ekström, M. (2009). Multi-model ensemble estimates of climate change impacts on UK seasonal precipitation extremes. International Journal of Climatology 29(3): 385-416.

Gangopadhyay, S., Clark, M., \& Rajagopalan, B. (2005). Statistical downscaling using K-nearest neighbors. Water Resources Research 41(2): W02024.

Giorgi, F., Jones, C., \& Asrar, G. R. (2009). Addressing climate information needs at the regional level: the CORDEX framework. World Meteorological Organization (WMO) Bulletin 58: 175-183.

Goodess, C.M. (2012). How is the frequency, location and severity of extreme events likely to change up to 2060 ? Environmental Science \& Policy 27: 4-14. 
Gregersen, I. et al. (2013). Assessing future climatic changes of rainfall extremes at small spatiotemporal scales. Climatic Change 118(3-4): 783-797.

Haberlandt, U., Belli, A., \& Bárdossy, A. (2014). Statistical downscaling of precipitation using a stochastic rainfall model conditioned on circulation patterns-an evaluation of assumptions. International Journal of Climatology 35(3): 417-432.

Hanel, M., \& Buishand, T. (2010). On the value of hourly precipitation extremes in regional climate model simulations. Journal of Hydrology 393(3): 265-273.

Hardwick Jones, R., Westra, S., \& Sharma, A. (2010). Observed relationships between extreme sub-daily precipitation, surface temperature, and relative humidity. Geophysical Research Letters 37(22): L22805.

Haylock, M., Hofstra, N., Klein Tank, A., Klok, E., Jones, P., \& New, M. (2008). A European daily highresolution gridded dataset of surface temperature and precipitation. Journal of Geophysical Research (Atmospheres) 113: D20119.

Hurrell, J., \& Trenberth, K. (2013). The Climate Data Guide: NCAR Sea Level Pressure. https://climatedataguide.ucar.edu/climate-data/ncar-sea-level-pressure Jacob, D. et al. (2014). EURO-CORDEX: new high resolution climate change projections for European impact research, Regional Environmental Change 14: 563-578.

Jones, M., Blenkinsop, S., Fowler, H., \& Kilsby, C. (2014). Objective classification of extreme rainfall regions for the UK and updated estimates of trends in regional extreme rainfall. International Journal of Climatology 34(3): 751-765.

This article is protected by copyright. All rights reserved. 
Kendon, E., Blenkinsop, S., \& Fowler, H. (2018). When will we detect changes in short-duration precipitation extremes? Journal of Climate 31(7): 2945-2964.

Kendon, E. et al. (2016). Do convection-permitting regional climate models improve projections of future precipitation change? Bulletin of the American Meteorological Society, https://journals.ametsoc.org/doi/pdf/10.1175/BAMS-D-15-0004.1

Kendon, E. et al. (2014). Heavier summer downpours with climate change revealed by weather forecast resolution model. Nature Climate Change 4: 570-576.

Kendon, E., Roberts, N., Senior, C., \& Roberts, M. (2012). Realism of rainfall in a very high resolution regional climate model. Journal of Climate 25(17): 5791-5806.

Kendon, E., Rowell, D., \& Jones, R. (2010). Mechanisms and reliability of future projected changes in daily precipitation. Climate Dynamics 35(2): 489-509.

Kirtman, B. et al. (2013). Near-term climate change: projections and predictability. Climate change 2013: The Physical Science Basis. Cambridge University Press, Cambridge. 953-1028.

Lenderink, G., \& van Meijgaard, E. (2008). Increase in hourly precipitation extremes beyond expectations from temperature changes. Nature Geoscience 1(8): 511-514.

Maraun, D. (2019). Statistical downscaling for Climate Science. Oxford Research Encyclopedia of Climate Science.

Maraun, D., Rust, H., \& Osborn, T. (2010a). Synoptic airflow and UK daily precipitation extremes. Extremes 13(2): 133-153. 
Maraun, D. et al. (2010b). Precipitation downscaling under climate change: Recent developments to bridge the gap between dynamical models and the end user. Reviews of Geophysics 48(3): RG3003.

Maraun, D., Osborn, T., \& Gillett, N. (2008). United Kingdom daily precipitation intensity: improved early data, error estimates and an update from 2000 to 2006. International Journal of Climatology 28(6): 833-842.

Mezghani, A., \& Hingray, B. (2009). A combined downscaling-disaggregation weather generator for stochastic generation of multisite hourly weather variables over complex terrain: Development and multi-scale validation for the Upper Rhone River basin. Journal of Hydrology 377(3): 245260.

Molnar, P. et al. (2014). Little evidence for super Clausius-Clapeyron scaling of intense rainstorm properties with air temperature. Hydrology and Earth System Sciences Discussions 11(7): 89238948.

Peleg, N., Molnar, P., Burlando, P., \& Fatichi, S. (2019). Exploring stochastic climate uncertainty in space and time using a gridded hourly weather generator. Journal of Hydrology 571: 627-641.

Prein, A., Rasmussen, R., Ikeda, K., Liu, C., Clark, M., \& Holland, G. (2017). The future intensification of hourly precipitation extremes. Nature Climate Change 7: 48-52.

Rau, M. (2016). Statistical downscaling of future hourly precipitation extremes in the UK using regional climate models and circulation patterns. Ph.D. thesis, University of East Anglia. 
Seneviratne, S. et al. (2012). Changes in climate extremes and their impacts on the natural physical environment. Managing the risks of extreme events and disasters to advance climate change adaptation. Cambridge University Press, Cambridge. 109-230.

Svoboda, V., Hanel, M., Máca, P., \& Kyselý, J. (2017). Characteristics of rainfall events in regional climate model simulations for the Czech Republic. Hydrology \& Earth System Sciences 21(2): 963-980.

Svoboda, V., Hanel, M., Máca, P., \& Kyselý, J. (2016). Projected changes of rainfall event characteristics for the Czech Republic. Journal of Hydrology \& Hydromechanics 64(4): 415-425.

Westra, S. et al. (2014). Future changes to the intensity and frequency of short-duration extreme rainfall. Reviews of Geophysics 52(3): 522-555.

Willems, P. \& Vrac, M. (2011). Statistical precipitation downscaling for small-scale hydrological impact investigations of climate change. Journal of Hydrology 402(3): 193-205.

Zorita, E. \& Von Storch, H. (1999). The analog method as a simple statistical downscaling technique: comparison with more complicated methods. Journal of climate 12(8): 2474-2489.

\section{Table captions}

Table 1. The four different approaches of subsampling within the process of finding the analogue day.

Table 2. The $99.5^{\text {th }}$ percentile differences between observed and estimated hourly precipitation in [\%] over the ten warmest summers for the time period 1980-2009. The estimates are derived from the ERA-interim driven RCA4 and RACMO22E data, respectively. M1-M4 are explained in 
Table 1. The mean temperature difference between the ten warmest summers and the 20 coldest summers is given in parenthesis after each station name.

Table 3. Same as Table 2 but estimates are derived from observed predictors instead of using ERA-interim driven RCM data.

Table 4. The simulated and observed CP frequencies in summer over the reference period 1980-2005 in [\%]. U stands for unclassified.

Table 5. Changes in [\%] of the projected $99.5^{\text {th }}$ percentile of daily precipitation in summer relative to the reference period $1980-2005$. The projections include three combinations, namely 2030-2055 (RCP4.5), 2075-2100 (RCP4.5) and 2075-2100 (RCP8.5). Negative changes are shown in italic.

Table 6. Changes in [\%] of the estimated median of the $99.5^{\text {th }}$ percentile of daily maximum hourly precipitation relative to the reference period $1980-2005$. The projections include three combinations, namely 2030-2055 (RCP4.5), 2075-2100 (RCP4.5) and 2075-2100 (RCP8.5). The median is calculated using 100 bootstrapping samples for each GCM driven RCM data set. Negative changes are shown in italic. The highest increase is highlighted in bold.

Table 7. The differences in [\%] between the estimated median changes of the $99.5^{\text {th }}$ percentile of daily maximum hourly precipitation using the perturbation process and the estimated median changes of the $99.5^{\text {th }}$ percentile of daily maximum hourly precipitation not using the 
perturbation process. The changes are given relative to the reference period 1980-2005. The projections include three combinations, namely 2030-2055 (RCP4.5), 2075-2100 (RCP4.5) and 2075-2100 (RCP8.5). The median is calculated using 100 bootstrapping samples for each GCM driven RCM data set. Negative differences are shown in italic, differences that are significant (at the $5 \%$ level) based on the $p$-value test are highlighted in bold.

\section{Figure captions}

Figure 1. The twelve final selected hourly precipitation stations across the UK based on the station selection criteria. The 14 different UK extreme precipitation regions as described in Jones et al. (2014) are represented by different colours.

Figure 2. Annual cycle of the $99.5^{\text {th }}$ hourly precipitation percentiles between $1980-2009$ for the twelve selected stations.

Figure 3. The flowchart diagram of the applied method to downscale extreme hourly precipitation. SLP stands for sea level pressure, P for precipitation and T for temperature.

Figure 4. Frequency distribution (above 0.6 ) of the simulated and observed daily precipitation in summer over the reference period 1980-2005 at Boscombe Down.

Figure 5. Frequency distribution of the simulated and observed daily temperature in summer over the reference period 1980-2005 at Boscombe Down. 
Figure 6. Changes in [\%] of the projected $99.5^{\text {th }}$ percentile of daily maximum hourly precipitation in comparison to the reference period 1980-2005 for the twelve final selected stations across the UK with the elevation map. The projections include three combinations: The left number shows the changes for 2030-2055 (RCP4.5), the centred number for 2075-2100 (RCP4.5) and the right number for 2075-2100 (RCP8.5). The changes are averaged over 100 bootstrapping samples for each GCM driven RCM data set. 
Table 1. The four different approaches of subsampling within the process of finding the analogue day.

\begin{tabular}{ll}
\hline Approach & Description \\
\hline M1 & $\begin{array}{l}\text { Calibration days are subsampled into two seasons (NDJFMA and MJJASO) and } \\
5(+1) \mathrm{CPs}\end{array}$ \\
M2 & Calibration days are subsampled into twelve calendar months and 5 (+1) CPs \\
M3 & $\begin{array}{l}\text { Calibration days are subsampled into two seasons (NDJFMA and MJJASO), } 5 \\
(+1) \text { CPs and daily precipitation categories (6) }\end{array}$ \\
M4 & $\begin{array}{l}\text { Calibration days are subsampled into twelve calendar months, } 5 \text { (+1) CPs and } \\
\text { daily precipitation categories (6) }\end{array}$
\end{tabular}

This article is protected by copyright. All rights reserved. 
Table 2. The $99.5^{\text {th }}$ percentile differences between observed and estimated hourly precipitation in [\%] over the ten warmest summers for the time period 1980-2009. The estimates are derived from the ERA-interim driven RCA4 and RACMO22E data, respectively. M1-M4 are explained in Table 1. The mean temperature difference between the ten warmest summers and the 20 coldest summers is given in parenthesis after each station name.

\begin{tabular}{|c|c|c|c|c|c|c|c|c|c|c|c|c|c|c|}
\hline & & 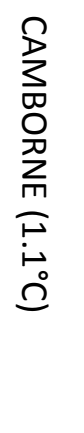 & 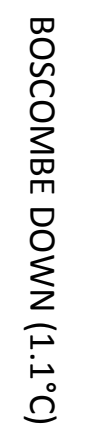 & 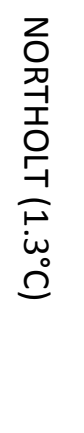 & 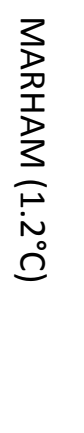 & 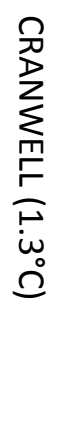 & 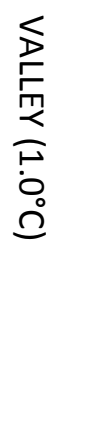 & 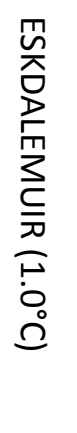 & 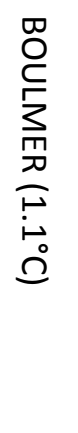 & 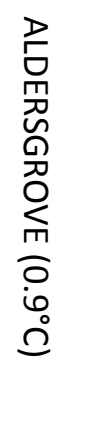 & 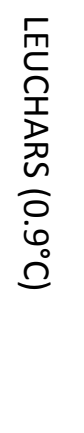 & $\begin{array}{l}\text { ㄱ } \\
\text { 而 } \\
\text { m } \\
\text { O } \\
\infty \\
0 \\
0\end{array}$ & 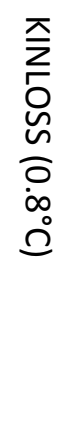 & $\frac{3}{\mathbf{m}}$ \\
\hline \multirow[t]{2}{*}{ M1 } & RCA4 & 8.0 & 9.2 & 11.5 & 10.1 & 17.8 & 18.1 & 27.6 & 8.8 & 14.0 & 18.2 & 9.5 & 18.1 & 14.2 \\
\hline & RACMO22E & 9.5 & 19.0 & 18.0 & 10.9 & 13.2 & 7.1 & 11.7 & 11.3 & 13.6 & 31.4 & 17.8 & 15.6 & 14.9 \\
\hline \multirow[t]{2}{*}{$\mathrm{M} 2$} & RCA4 & 10.2 & 10.0 & 15.6 & 8.4 & 22.1 & 27.4 & 30.7 & 16.0 & 10.4 & 20.4 & 8.9 & 17.4 & 16.5 \\
\hline & RACMO22E & 6.8 & 8.2 & 11.1 & 14.7 & 14.6 & 26.2 & 4.8 & 8.7 & 10.4 & 29.8 & 17.4 & 10.0 & 13.6 \\
\hline \multirow[t]{2}{*}{ M3 } & RCA4 & 15.2 & 14.8 & 24.3 & 16.0 & 24.4 & 10.2 & 24.4 & 14.9 & 13.5 & 18.6 & 7.5 & 75.5 & 21.6 \\
\hline & RACMO22E & 14.8 & 11.7 & 10.5 & 13.5 & 8.0 & 5.3 & 15.1 & 28.3 & 12.4 & 13.2 & 26.3 & 64.7 & 18.7 \\
\hline \multirow[t]{2}{*}{ M4 } & RCA4 & 17.1 & 10.4 & 20.4 & 7.1 & 29.7 & 23.8 & 28.0 & 29.0 & 13.9 & 35.8 & 16.2 & 9.3 & 20.1 \\
\hline & RACMO22E & 12.5 & 13.8 & 11.1 & 10.3 & 7.1 & 45.4 & 10.8 & 32.6 & 17.6 & 18.8 & 14.4 & 13.8 & 17.4 \\
\hline
\end{tabular}


Table 3. Same as Table 2 but estimates are derived from observed predictors instead of using ERA-interim driven RCM data.

\begin{tabular}{|c|c|c|c|c|c|c|c|c|c|c|c|c|c|}
\hline & 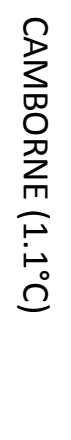 & 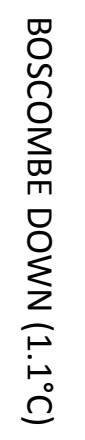 & 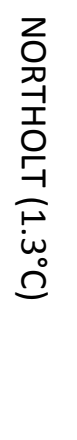 & 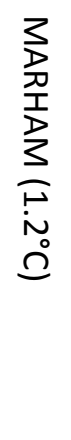 & 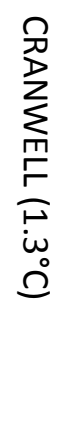 & 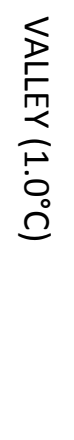 & 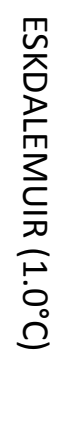 & 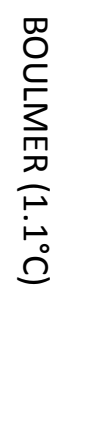 & 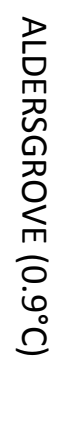 & 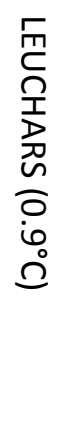 & 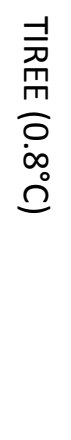 & 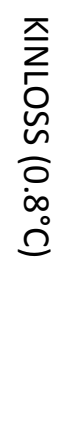 & $\frac{3}{2}$ \\
\hline M1 & 6.8 & 15.6 & 10.5 & 4.8 & 7.7 & 8.2 & 6.7 & 8.0 & 11.9 & 7.7 & 7.6 & 11,1 & 8.8 \\
\hline $\mathrm{M} 2$ & 8.1 & 17.5 & 8.6 & 7.9 & 6.4 & 7.4 & 6.0 & 10.2 & 21.5 & 9.1 & 7.1 & 19.3 & 10.8 \\
\hline M3 & 9.5 & 11.3 & 15.7 & 7.0 & 8.9 & 9.3 & 18.3 & 8.7 & 10.8 & 6.9 & 6.2 & 9.7 & 10.2 \\
\hline M4 & 8.1 & 20.5 & 15.1 & 7.4 & 6.9 & 7.3 & 5.7 & 12.7 & 10.9 & 7.2 & 5.5 & 16.6 & 10.3 \\
\hline
\end{tabular}


Table 4. The simulated and observed CP frequencies in summer over the reference period 1980-2005 in [\%]. U stands for unclassified.

\begin{tabular}{llllllll}
\hline RCM & GCM & CP1 & CP2 & CP3 & CP4 & CP5 & U \\
& & & & & & & \\
\hline RCA4 & ERA-Interim & 7.1 & 15.6 & 28.5 & 25.2 & 18.5 & 5.1 \\
RCA4 & CM5A-MR & 7.3 & 14.7 & 28.0 & 27.5 & 17.3 & 5.1 \\
RCA4 & ESM-LR & 6.9 & 13.1 & 30.0 & 25.6 & 19.0 & 5.4 \\
RCA4 & EC-EARTH & 8.6 & 13.9 & 29.0 & 24.9 & 18.6 & 5.2 \\
RACMO22E & ERA-Interim & 8.0 & 14.7 & 29.6 & 25.2 & 17.6 & 4.9 \\
RACMO22E & EC-EARTH & 10.0 & 13.6 & 27.5 & 25.7 & 19.4 & 3.8 \\
\hline \multirow{2}{*}{ Observed } & -- & 7.8 & 15.9 & 29.3 & 24.8 & 18.0 & 4.3
\end{tabular}


Table 5. Changes in [\%] of the projected $99.5^{\text {th }}$ percentile of daily precipitation in summer relative to the reference period $1980-2005$. The projections include three combinations, namely 2030-2055 (RCP4.5), 2075-2100 (RCP4.5) and 2075-2100 (RCP8.5). Negative changes are shown in italic.

\begin{tabular}{|c|c|c|c|c|c|c|c|c|c|c|c|c|c|}
\hline RCM & GCM & 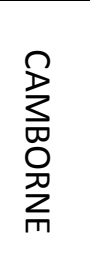 & 号 & $\begin{array}{l}Z \\
0 \\
\text { 억 } \\
\text { T⿱一土 } \\
\text { 음 }\end{array}$ & $\begin{array}{l}3 \\
D \\
\frac{1}{1} \\
\frac{1}{3}\end{array}$ & 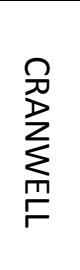 & 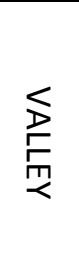 & 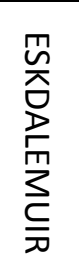 & 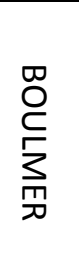 & 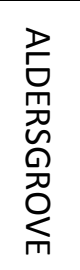 & 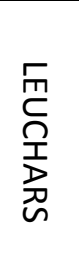 & $\begin{array}{l}\text { 검 } \\
\text { 而 }\end{array}$ & 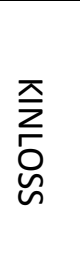 \\
\hline \multicolumn{14}{|c|}{ 2030-2055 (RCP 4.5) } \\
\hline RCA4 & CM5A-MR & 16.3 & -10.3 & 9.8 & -9.6 & -1.4 & -5.9 & 2.5 & 16.3 & 5.1 & 10.0 & 6.3 & -13.5 \\
\hline RCA4 & ESM-LR & -5.5 & -3.2 & 7.0 & -8.5 & 3.4 & 1.4 & 2.6 & -7.3 & -8.5 & 4.0 & -9.2 & 4.0 \\
\hline RCA4 & EC-EARTH & 8.1 & 11.1 & 4.5 & -4.2 & -5.6 & 11.2 & 11.5 & -3.8 & 13.1 & -4.0 & -1.7 & -6.0 \\
\hline RACMO22E & EC-EARTH & 7.4 & 9.1 & -1.3 & 12.2 & 7.1 & -2.2 & -1.0 & 17.0 & -5.9 & 13.7 & 10.0 & 20.6 \\
\hline \multicolumn{2}{|c|}{ MEAN } & 8.8 & 1.7 & 5.0 & -2.5 & 0.9 & 1.1 & 3.9 & 5.6 & 1.0 & 5.9 & 1.4 & 1.3 \\
\hline \multicolumn{14}{|c|}{$2075-2100$ (RCP 4.5) } \\
\hline RCA4 & CM5A-MR & 28.0 & 15.9 & 9.1 & 6.3 & 13.8 & 4.3 & 10.1 & 28.7 & -3.4 & 13.4 & 10.7 & 13.9 \\
\hline RCA4 & ESM-LR & -4.3 & 2.2 & -1.5 & -0.2 & 2.7 & -2.0 & -0.7 & -0.3 & -7.5 & 14.4 & 7.0 & -3.9 \\
\hline RCA4 & EC-EARTH & 11.2 & 25.5 & 2.5 & 4.3 & 16.9 & 7.5 & 14.5 & 8.4 & 4.5 & 9.2 & 6.9 & -7.3 \\
\hline RACMO22E & EC-EARTH & 1.3 & 3.6 & -0.2 & 21.4 & 22.2 & 29.7 & 1.5 & 12.1 & 3.2 & 17.9 & 9.3 & 4.1 \\
\hline \multicolumn{2}{|c|}{ MEAN } & 9.1 & 11.8 & 23.1 & 8.0 & 13.9 & 9.9 & 6.4 & 12.2 & -0.8 & 13.7 & 8.5 & 1.7 \\
\hline \multicolumn{14}{|c|}{$2075-2100$ (RCP 8.5) } \\
\hline RCA4 & CM5A-MR & 5.3 & 8.9 & 10.0 & 1.6 & 17.4 & 12.4 & 24.8 & 28.7 & 22.7 & 9.2 & 21.7 & 26.8 \\
\hline RCA4 & ESM-LR & 16.2 & 8.5 & 20.6 & 10.4 & 3.8 & 17.8 & 9.6 & 11.9 & 11.3 & 14.1 & 12.9 & 9.5 \\
\hline RCA4 & EC-EARTH & 24.6 & 27.6 & 17.1 & 13.6 & 14.9 & 24.3 & 22.7 & 8.6 & 18.5 & 19.9 & 5.7 & 3.0 \\
\hline RACMO22E & EC-EARTH & 11.0 & 13.4 & 22.9 & 26.6 & 24.2 & 19.6 & 13.7 & 18.9 & 11.4 & 18.0 & 27.6 & 8.2 \\
\hline \multicolumn{2}{|c|}{ MEAN } & 14.3 & 14.6 & 17.7 & 13.1 & 15.1 & 18.5 & 17.7 & 17.0 & 16.0 & 15.3 & 17.0 & 11.9 \\
\hline
\end{tabular}

This article is protected by copyright. All rights reserved. 
Table 6. Changes in [\%] of the estimated median of the $99.5^{\text {th }}$ percentile of daily maximum hourly precipitation relative to the reference period $1980-2005$. The projections include three combinations, namely 2030-2055 (RCP4.5), 2075-2100 (RCP4.5) and 2075-2100 (RCP8.5). The median is calculated using 100 bootstrapping samples for each GCM driven RCM data set. Negative changes are shown in italic. The highest increase is highlighted in bold.

\begin{tabular}{|c|c|c|c|c|c|c|c|c|c|c|c|c|c|}
\hline RCM & GCM & 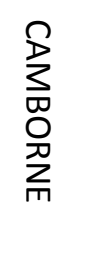 & 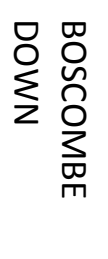 & 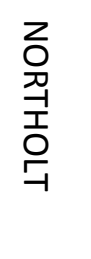 & $\begin{array}{l}3 \\
D \\
D \\
I \\
3\end{array}$ & 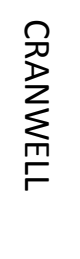 & 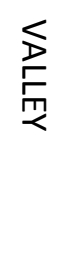 & 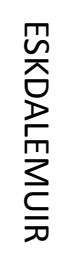 & $\begin{array}{l}\text { 吕 } \\
\subseteq \\
\text { 夏 } \\
\text { 盀 }\end{array}$ & 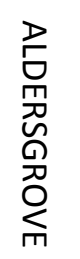 & 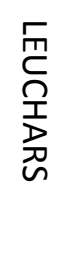 & $\begin{array}{l}\text { ㄱ } \\
\text { D } \\
\text { m }\end{array}$ & 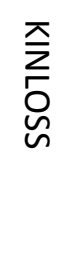 \\
\hline \multicolumn{14}{|c|}{ 2030-2055 (RCP 4.5) } \\
\hline RCA4 & CM5A-MR & 6.3 & -5.9 & 25.5 & 2.3 & 0.0 & 4.3 & 38.4 & 1.9 & 16.7 & 23.9 & 4.1 & 43.3 \\
\hline RCA4 & ESM-LR & 12.0 & 12.1 & 27.6 & 3.7 & 6.2 & 3.3 & 27.1 & -4.6 & -3.4 & 8.6 & 1.6 & 6.8 \\
\hline RCA4 & EC-EARTH & -6.9 & 15.8 & 27.1 & 1.4 & 1.7 & 2.2 & 12.7 & 3.7 & 22.7 & 12.6 & -0.9 & 7.2 \\
\hline RACMO22E & EC-EARTH & 5.9 & -0.1 & 9.8 & 2.0 & -1.1 & -1.6 & 51.5 & 9.6 & 2.4 & 11.9 & -7.3 & 19.8 \\
\hline \multicolumn{2}{|c|}{ MEAN } & 4.3 & 5.5 & 22.5 & 2.4 & 1.7 & 2.1 & 32.4 & 2.7 & 9.6 & 14.3 & -0.6 & 19.3 \\
\hline \multicolumn{14}{|c|}{$2075-2100$ (RCP 4.5) } \\
\hline RCA4 & CM5A-MR & 21.0 & 2.9 & 36.7 & 3.1 & 16.6 & 4.6 & 62.7 & 20.6 & -2.4 & 26.0 & 10.1 & 14.2 \\
\hline RCA4 & ESM-LR & 8.9 & 13.4 & 22.4 & 7.9 & 7.3 & -0.5 & 19.9 & 3.7 & 9.6 & 12.9 & 2.0 & 75.9 \\
\hline RCA4 & EC-EARTH & 8.4 & 26.4 & 32.8 & 0.7 & 3.5 & 0.0 & 5.2 & 3.6 & 17.1 & 22.6 & 10.2 & 59.2 \\
\hline RACMO22E & EC-EARTH & 2.1 & -5.3 & 0.4 & 4.2 & 13.3 & 4.9 & 2.3 & 17.3 & 6.3 & 22.4 & -3.0 & 25.4 \\
\hline \multicolumn{2}{|c|}{ MEAN } & 10.1 & 9.4 & 23.1 & 4.0 & 10.2 & 2.3 & 22.5 & 11.3 & 7.7 & 21.0 & 4.8 & 43.7 \\
\hline \multicolumn{14}{|c|}{ 2075-2100 (RCP 8.5) } \\
\hline RCA4 & CM5A-MR & 22.1 & 13.1 & 41.9 & 14.2 & 29.4 & 28.0 & 37.1 & 31.8 & 25.2 & 39.5 & 24.8 & 36.9 \\
\hline RCA4 & ESM-LR & 21.9 & 15.0 & 43.9 & 10.5 & 27.7 & 25.7 & 36.2 & 9.8 & 11.0 & 18.8 & 13.1 & 85.8 \\
\hline RCA4 & EC-EARTH & 10.8 & 28.9 & 46.2 & 15.6 & 18.2 & 9.3 & 31.7 & 15.9 & 29.8 & 23.2 & 9.2 & 111.9 \\
\hline RACMO22E & EC-EARTH & 22.0 & 12.2 & 21.3 & 12.2 & 10.2 & 18.6 & 78.0 & 20.9 & 13.0 & 23.8 & 1.2 & 65.9 \\
\hline \multicolumn{2}{|c|}{ MEAN } & 19.2 & 17.3 & 38.3 & 13.1 & 21.4 & 20.4 & 45.8 & 19.6 & 19.8 & 26.3 & 12.1 & 75.0 \\
\hline
\end{tabular}


Table 7. The differences in [\%] between the estimated median changes of the $99.5^{\text {th }}$ percentile of daily maximum hourly precipitation using the perturbation process and the estimated median changes of the $99.5^{\text {th }}$ percentile of daily maximum hourly precipitation not using the perturbation process. The changes are given relative to the reference period 1980-2005. The projections include three combinations, namely 2030-2055 (RCP4.5), 2075-2100 (RCP4.5) and 2075-2100 (RCP8.5). The median is calculated using 100 bootstrapping samples for each GCM driven RCM data set. Negative differences are shown in italic, differences that are significant (at the $5 \%$ level) based on the $p$-value test are highlighted in bold.

\begin{tabular}{|c|c|c|c|c|c|c|c|c|c|c|c|c|c|}
\hline RCM & GCM & $\begin{array}{l}\Omega \\
3 \\
\text { D } \\
0 \\
\text { 备 } \\
\text { m }\end{array}$ & 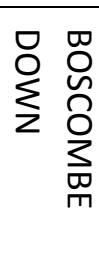 & 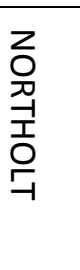 & 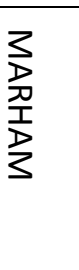 & 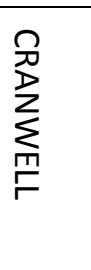 & 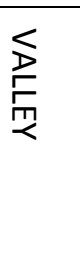 & 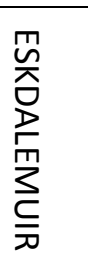 & 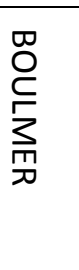 & 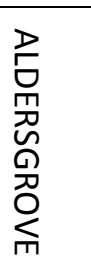 & 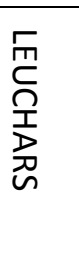 & $\begin{array}{l}\text { 豆 } \\
\text { 皿 }\end{array}$ & 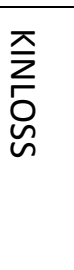 \\
\hline \multicolumn{14}{|c|}{ 2030-2055 (RCP 4.5) } \\
\hline RCA4 & CM5A-MR & -0.2 & 1.9 & -3.6 & 0.2 & 0.5 & -4.4 & -36.4 & 0.8 & -3.7 & 1.9 & -2.1 & 1.3 \\
\hline RCA4 & ESM-LR & 3.0 & -0.4 & 4.0 & 2.6 & 3.0 & -1.4 & -0.9 & 0.0 & 0.1 & 2.0 & -1.4 & -3.0 \\
\hline RCA4 & EC-EARTH & 1.1 & 3.3 & 3.1 & 0.5 & 1.1 & 0.7 & 0.5 & 0.7 & 1.0 & -0.1 & 0.5 & -0.8 \\
\hline RACMO22E & EC-EARTH & 0.4 & -0.3 & 1.3 & 0.2 & 0.8 & -3.7 & 27.8 & -4.2 & -2.1 & 0.5 & -4.4 & 0.0 \\
\hline \multicolumn{2}{|c|}{ MEAN } & 1.1 & 1.1 & 1.2 & 0.9 & 1.4 & -2.2 & -2.3 & -0.7 & -1.2 & 1.1 & -1.9 & -0.6 \\
\hline \multicolumn{14}{|c|}{$2075-2100$ (RCP 4.5) } \\
\hline RCA4 & CM5A-MR & 0.8 & 1.5 & 2.9 & 0.0 & 8.2 & -0.6 & -19.6 & 7.7 & -1.4 & 0.2 & 0.1 & 3.6 \\
\hline RCA4 & ESM-LR & -0.9 & -0.5 & 2.0 & 2.0 & 2.7 & -0.2 & -12.1 & -0.4 & -0.4 & 1.0 & 1.7 & 3.1 \\
\hline RCA4 & EC-EARTH & 0.7 & 5.2 & 7.4 & -0.5 & 9.8 & 5.6 & -2.2 & 1.0 & 2.0 & 1.2 & 2.0 & -2.5 \\
\hline
\end{tabular}




\begin{tabular}{|c|c|c|c|c|c|c|c|c|c|c|c|c|c|}
\hline RACMO22E & EC-EARTH & 1.3 & 0.5 & 2.1 & -2.8 & -1.0 & -1.0 & 2.8 & -2.5 & -0.6 & -1.9 & -1.3 & -0.7 \\
\hline \multicolumn{2}{|c|}{ MEAN } & 0.5 & 1.7 & 3.6 & -0.3 & 4.9 & 1.0 & -7.8 & 1.5 & -0.1 & 0.1 & 0.6 & 0.9 \\
\hline \multicolumn{14}{|c|}{ 2075-2100 (RCP 8.5) } \\
\hline RCA4 & CM5A-MR & 4.1 & 2.8 & 6.3 & 7.4 & 9.7 & 2.9 & -38.0 & 1.4 & 0.5 & 0.4 & -0.4 & -1.3 \\
\hline RCA4 & ESM-LR & 1.2 & 1.0 & 6.5 & 4.2 & 8.6 & 2.5 & -25.8 & 0.2 & -0.4 & 3.2 & -0.6 & 0.2 \\
\hline RCA4 & EC-EARTH & 0.2 & 6.1 & 8.5 & 3.5 & 8.6 & 0.0 & -2.6 & 5.3 & -1.8 & 1.2 & 3.1 & -1.1 \\
\hline RACMO22E & EC-EARTH & -1.4 & 1.2 & 3.3 & -0.1 & 1.9 & -0.7 & -12.3 & -5.2 & -0.9 & -3.1 & -2.8 & 5.3 \\
\hline \multicolumn{2}{|c|}{ MEAN } & 1.0 & 2.8 & 6.2 & 3.8 & 7.2 & 1.2 & -19.7 & 0.4 & -0.7 & 0.4 & -0.2 & 0.8 \\
\hline
\end{tabular}



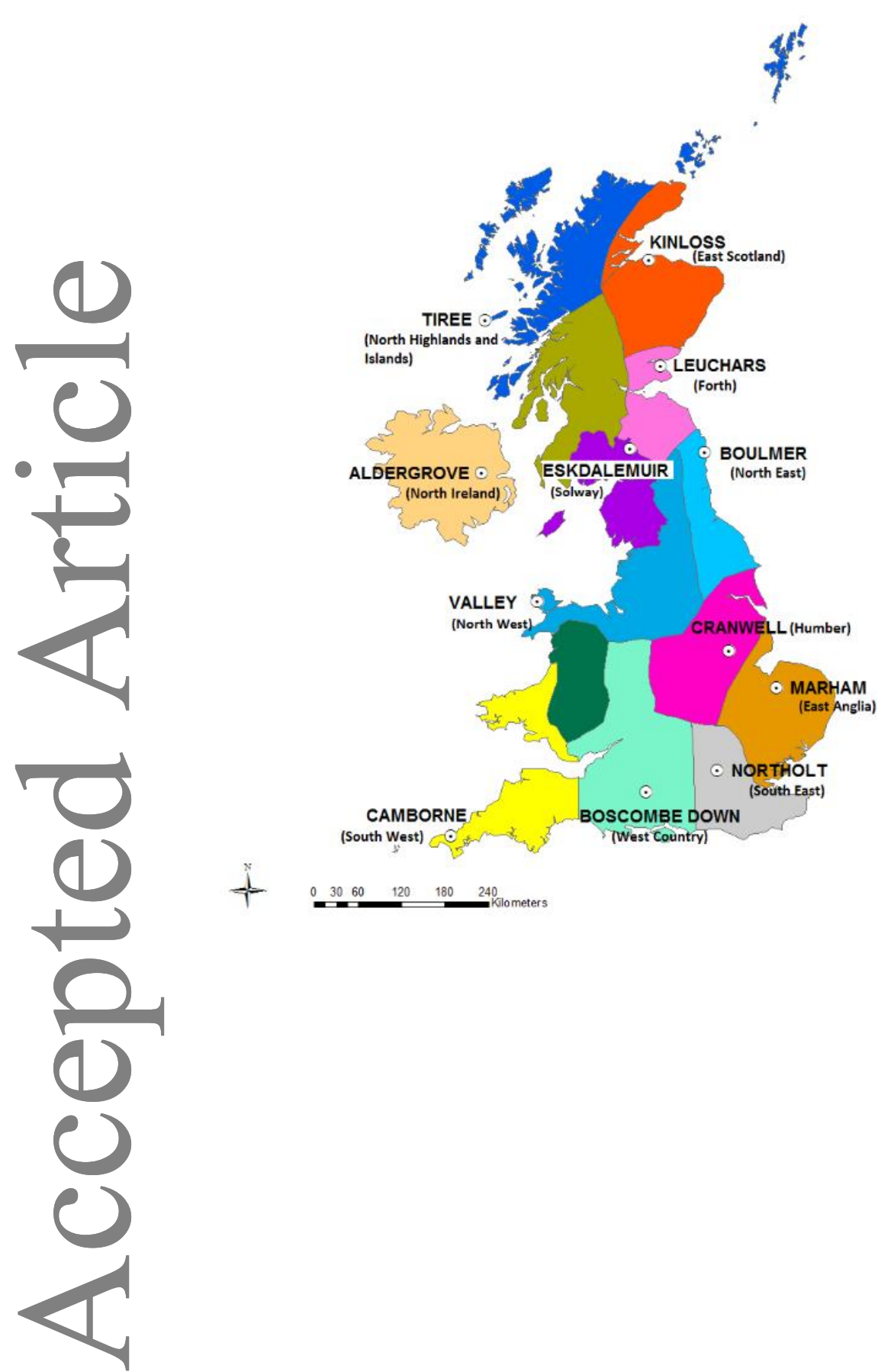

A statistical downscaling method based on circulation patterns (CPs) is developed to project site-specific extreme hourly precipitation for 12 different precipitation regions across the UK. The applied statistical downscaling is best described as a hybrid of the analogue and the regression-based method. It is found that increases in extreme hourly precipitation can be as high as $112 \%$ but are highly variable depending on the rainfall stations, the future time periods, the emission scenarios and the different RCM runs. 


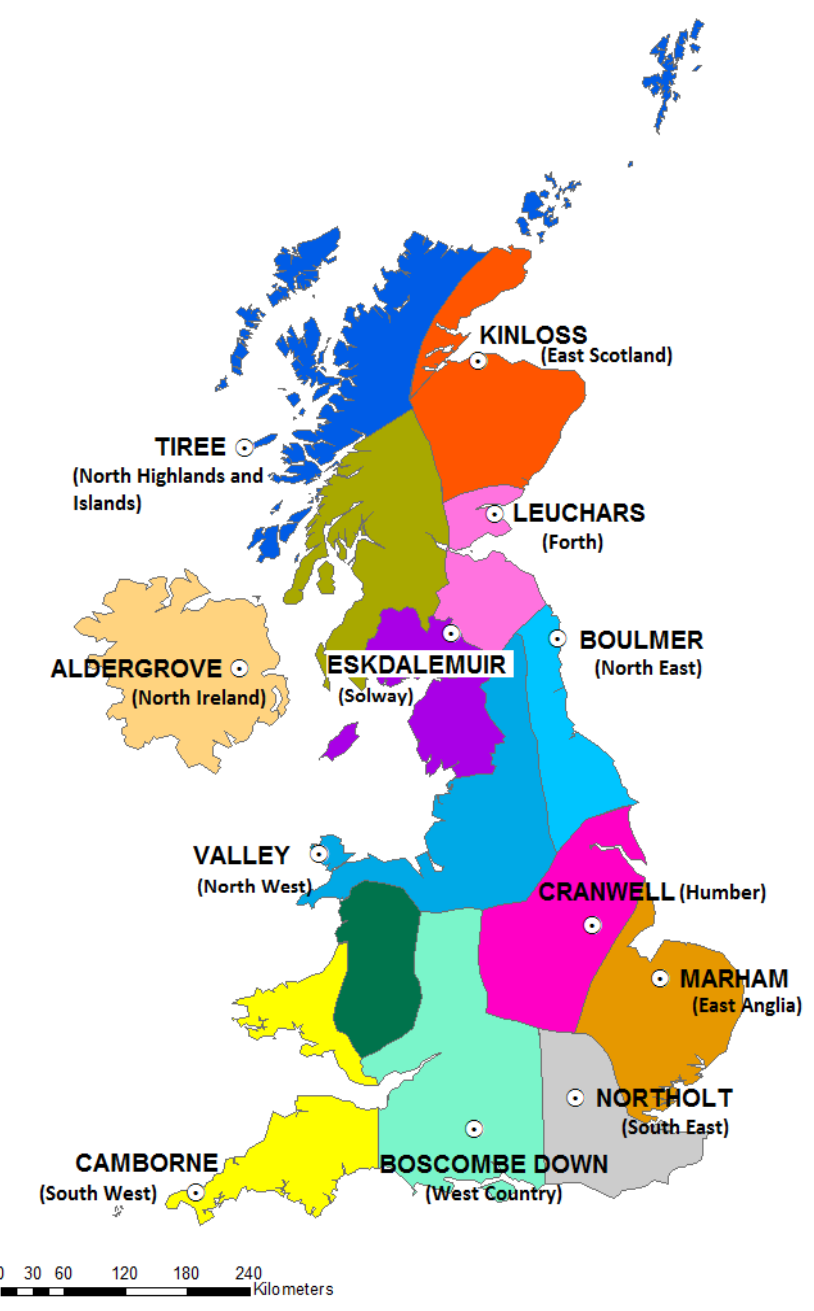

This article is protected by copyright. All rights reserved. 

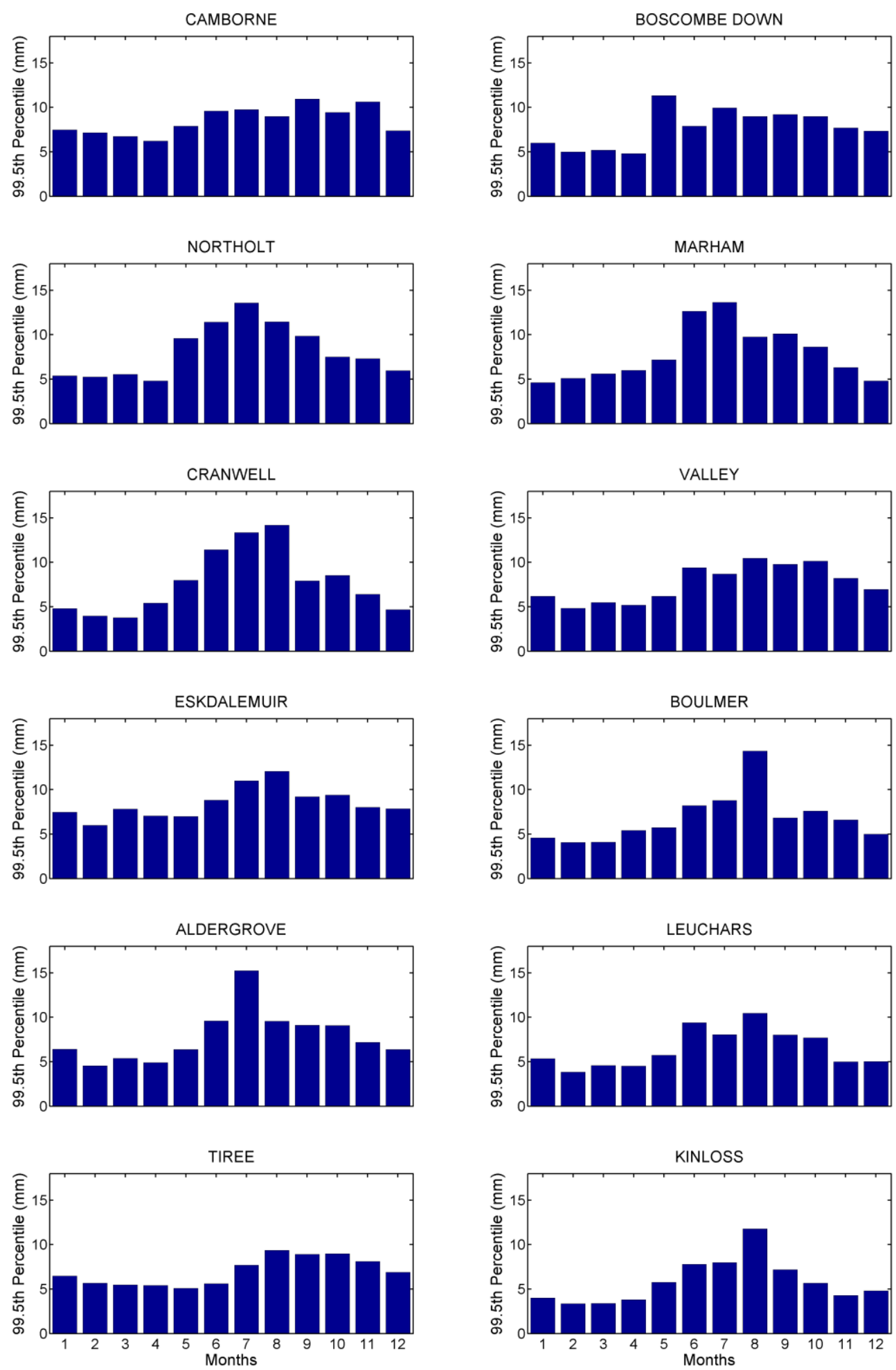


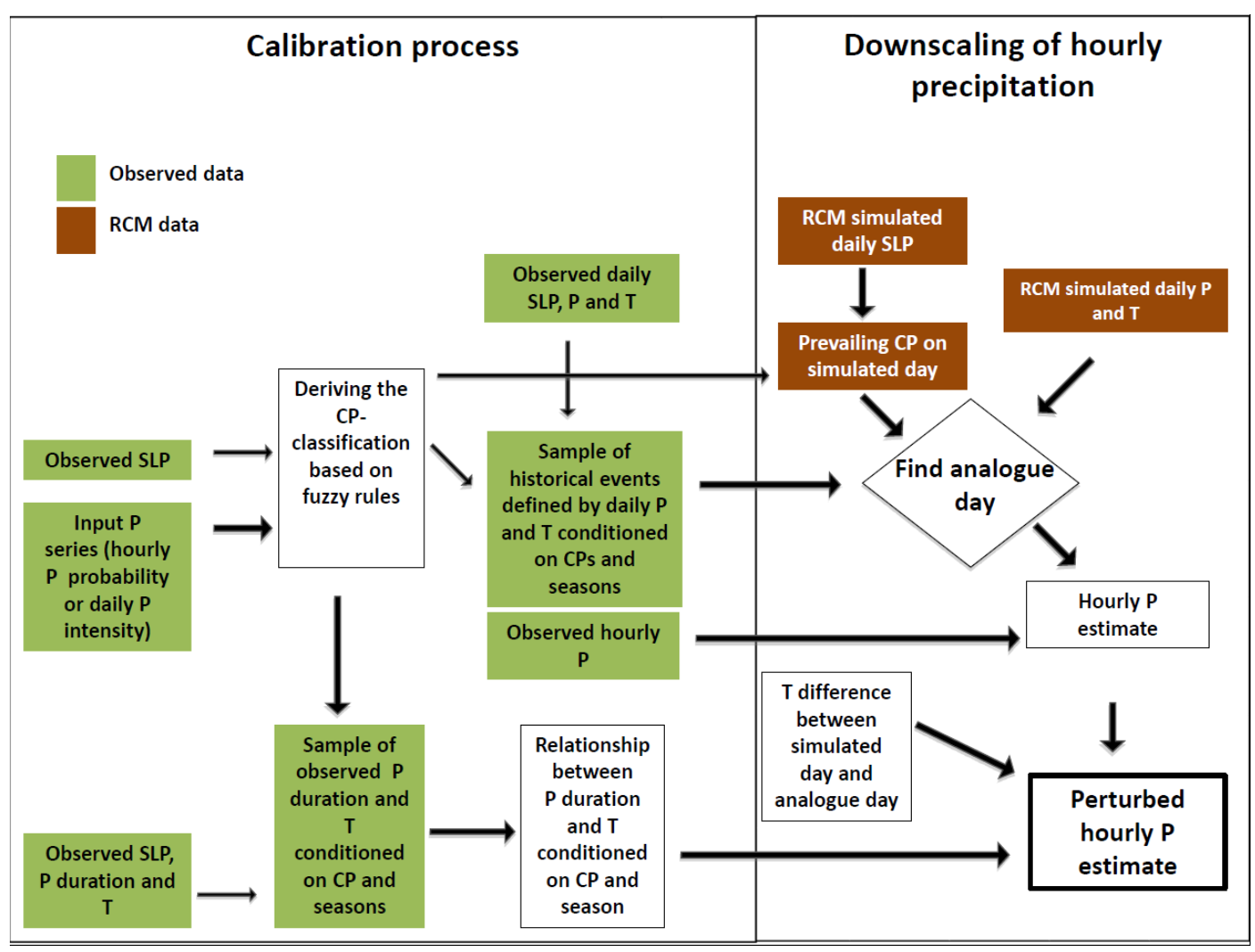

This article is protected by copyright. All rights reserved. 

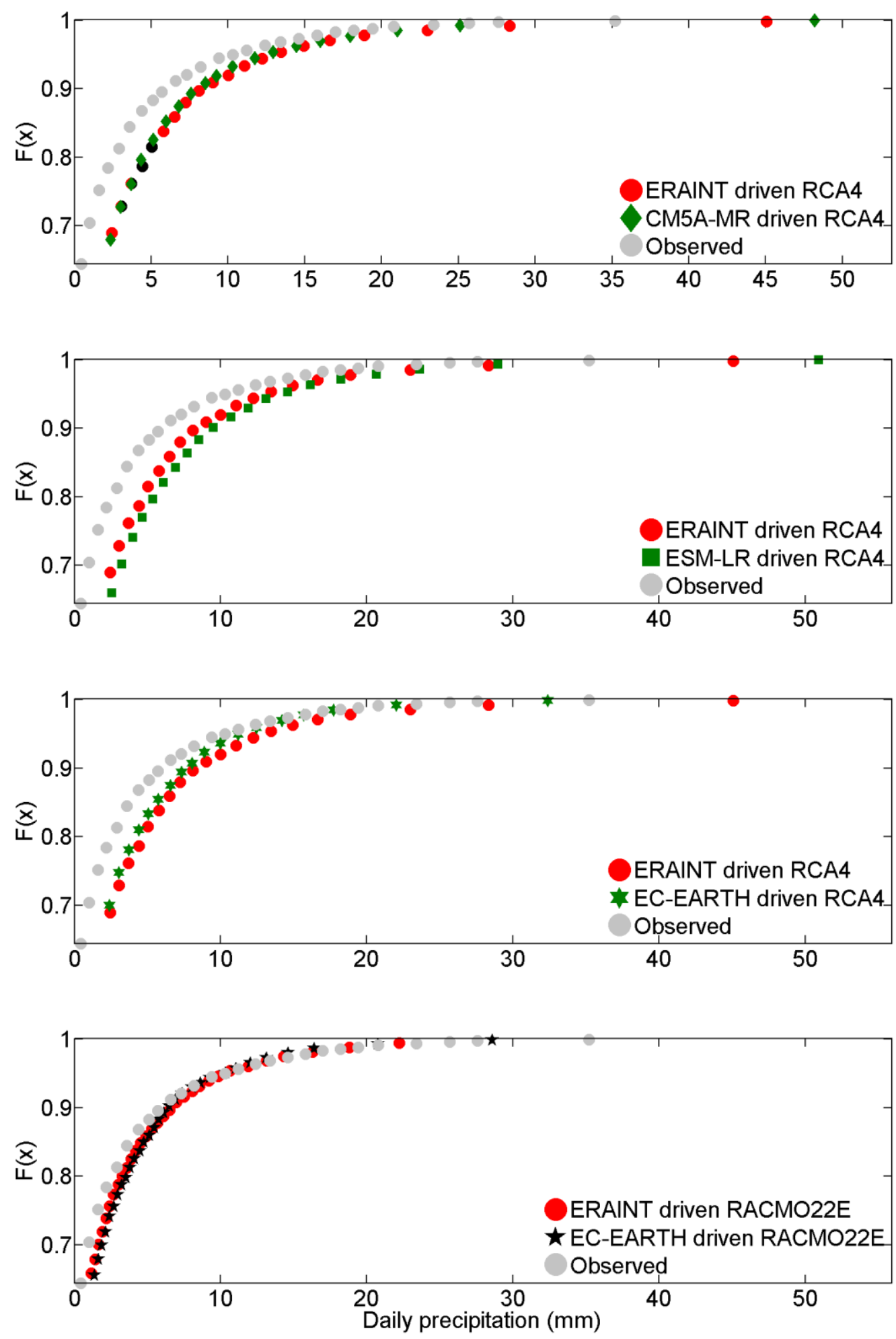

This article is protected by copyright. All rights reserved. 

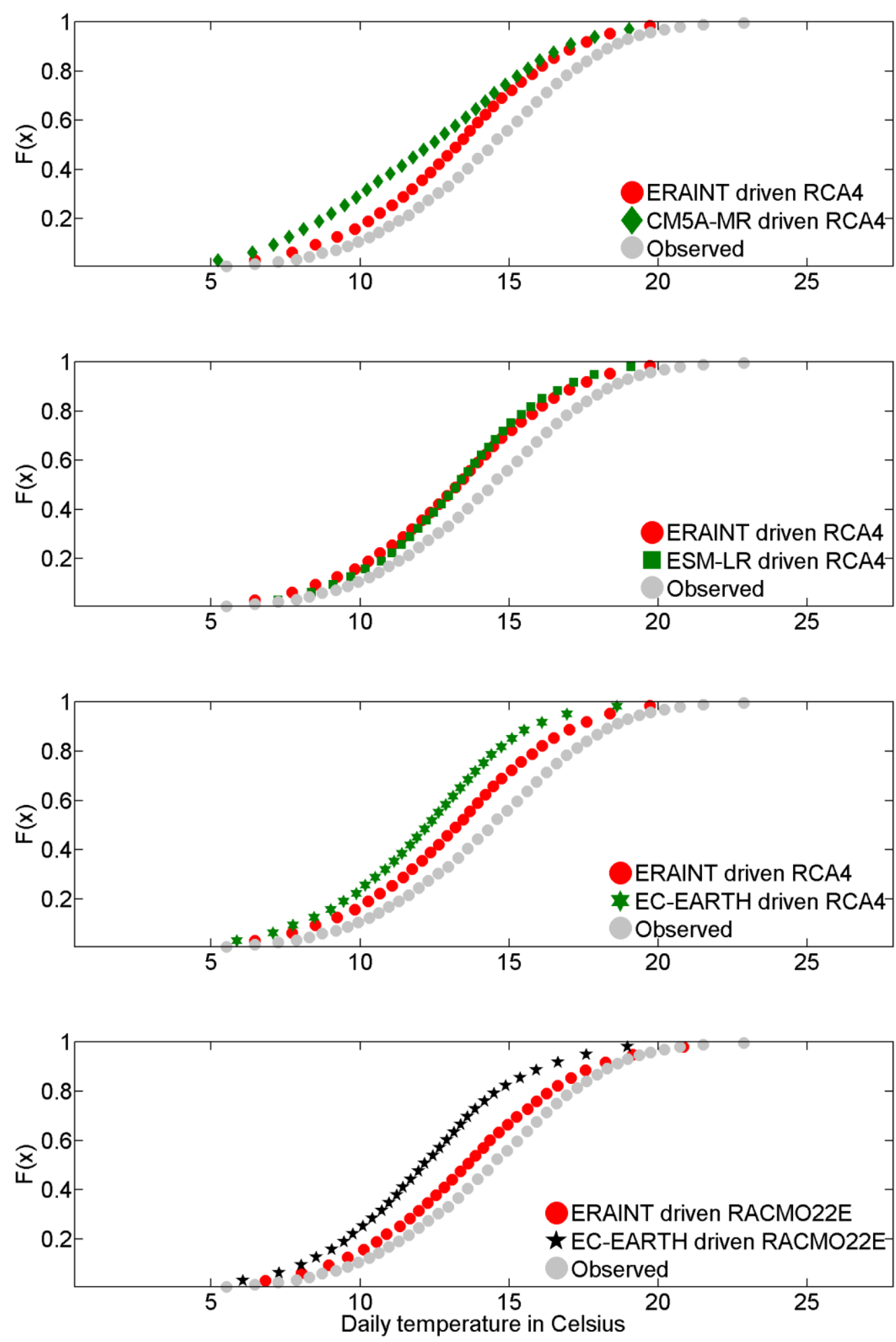

This article is protected by copyright. All rights reserved. 


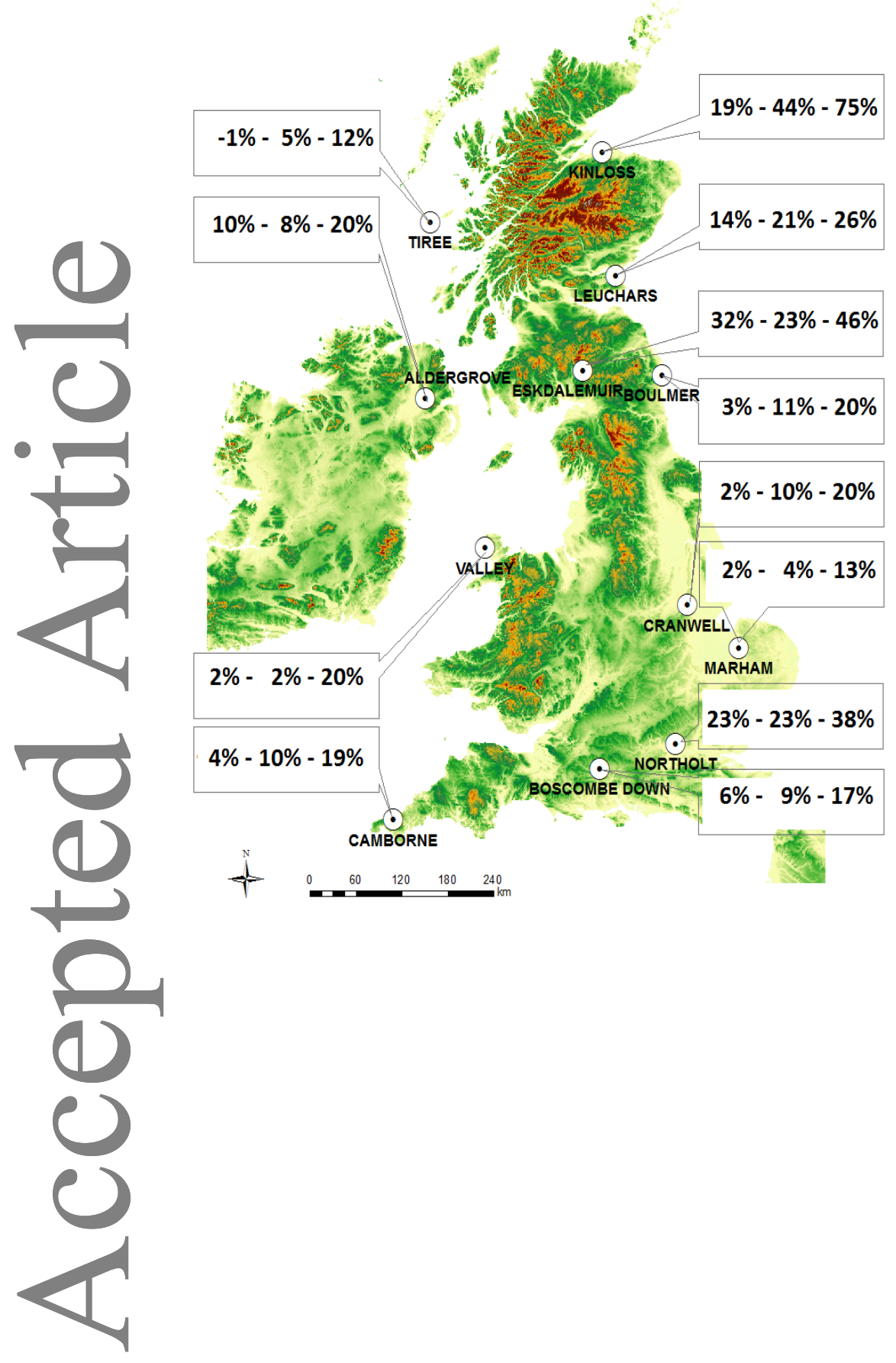

This article is protected by copyright. All rights reserved. 